\title{
Evaluation and Analysis of Renewable Energy Sources Potential in Slovenia and its Compatibility Examination with Slovenian National Renewable Energy Action Plan
}

\author{
Matevž Obrecht ${ }^{1,{ }^{*}}$, Matjaž Denac ${ }^{1}$, Patricija Furjan ${ }^{1}$, Milena Delčnjak ${ }^{2}$ \\ ${ }^{1}$ University of Maribor, Faculty of Economics and Business, Maribor, Slovenia \\ ${ }^{2}$ SODO d.o.o., Electricity distribution system operator, Maribor, Slovenia \\ * Matevž Obrecht, Tel: +386 40565128, Fax: +386 22296571, E-mail: matevz.obrecht@uni-mb.si
}

\begin{abstract}
Environmental problems and high import dependency from fossil fuels are core problems of the energy policy of the European Union (EU), therefore the EU has committed to increase the share of renewable energy sources (RES) in final energy consumption to $20 \%$ by 2020 . Individual targets for each EU member must be incorporated in National Renewable Energy Action Plan (NREAP). To evaluate the possibilities for development of sustainable energy industry and for preparation of NREAP, evaluation of future energy needs must be made, national RES potentials must be examined and increase of RES share must be planed. In this paper the energy balance and the consumption structure of energy sources in Slovenia, EU and the World is analyzed. The share and growth of RES in Slovenian energy balance is compared with the average values of EU and the World, with emphasis on examining RES potential in Slovenia. Compatibility of RES potentials with the planed utilization for individual RES potentials in Slovenia is analyzed from economic and technological point of view with environmental considerations taken into account. The purpose is to examine which RES potentials have not been fully exploited and compatibility of measures provided in Slovenian NREAP with the estimated potential of RES.
\end{abstract}

Keywords: Energy, Renewable energy sources, Energy Policy, Slovenia, Potentials

\section{Introduction}

In the 20th century, dramatic 20 fold increase of energy consumption has been noticed [1]. It is expected that the energy consumption will also rise in the future. The forecast of International Energy Agency (IEA) in its reference scenario estimate, that world energy demand from 2005 to 2030 will rise for approximately 52\% [2], while predictions of World energy council estimate double energy demand by 2050 what is comparable to IEA. Other recent estimates suggest that energy demand over the next five years will rise $2.5 \%$ annually and after that for $1.5 \%$ annually by 2030 . Fossil fuels will remain the major energy source, which will cover approximately three quarters of elevated energy needs.

The amount of fossil fuels consumed annually (about $80 \%$ of the total energy consumption) is about 7.5 bi llion tons when converted to carbon units (toe). Because the current world population is more than 6.86 billion people, the average consumption of fossil fuel energy by the people of the world at the turn of the century was just a little more than one ton per person. World average in annual energy consumption in 2008 was approximately 1.44 toe per capita. Calculation based on the data in national energy balance [3] shows, that the average consumption of fossil fuels in Slovenia is about $50 \%$ higher than the world average while average annual energy consumption in Slovenia is 2.38 toe, which is $65 \%$ more than world average what, on this criteria, range Slovenia among developed countries. Energy mixes of the members of EU-27 typically include approximately $60 \%$ of fossil fuels. IEA noted that predicted increase of energy demand in the next twenty years will have as imultaneous influence on increased prices of energy sources and increased green house gas (GHG) emissions. That is why IEA is drawing attention to the problems of fossil fuels consumption and calls for international climate agreement to cut GHG emissions. Continuous increase of 
energy consumption in Slovenia in the past and the future expectations are not sustainable and energy related emissions are already around $80 \%$ of all GHG emissions in Slovenia [4].

Pollution, GHG emissions, rising energy demand and high import dependency of energy are the core of energy problems in EU as well as in Slovenia. That is why RES are seen as a longterm solution and a short-term reduction of the above stated problems. The EU is aware of the issues related to conventional energy sources (CES) and supports the development of RES and sustainable energy. Sustainable energy comprises two key components: energy efficiency (EE) and RES. The investments in EE and RES are highly important since RES causes less or no pollution, enables use of local resources, lowers import dependency and increases EU competitiveness at the same time.

First ambitious goal set in EU in 2001 for the EU Member States, was 12\% share of RES in 2010 , which is unlikely to be reached. Second goal is represented in 20/20/20 objectives that require $20 \%$ of RES in EU by 2020 . Specific target for Slovenia is $25 \%$ of RES. Achieving this objective is encouraged also with renewable energy Directive (2009/28/EC) that requires Member States to submit NREAP by 30th June of 2010. These plans had to be prepared in accordance with the template published by the Commission, provided detailed roadmaps of how each Member State expected to reach its legally binding 2020 target for the share of RES in their final energy consumption. Member States had to set out the sectoral targets, the technology mix they expected to use, the trajectory they would follow and the measures and reforms they would undertake.

The ever-growing worldwide consumption of fossil fuels and the concomitant emissions as well as the limited availability of fossil fuels, have led to a growing interest in the application of RES, therefore RES potentials must be examined. The increased general awareness of the negative environmental impact of the use of fossil fuels demands sustainable alternative energy sources. To enable further growth of sustainable energy sector, energy consumption and RES share must be examined, that is why we are analyzing and comparing energy consumption and RES share between 2000 and 2010 in Slovenia, EU and the World. We are also examining and evaluating individual RES potential. Total, technical and economic potentials of individual RES and plans of Slovenian energy policy are analyzed and additionally evaluated with our own recognitions and calculations. Our thesis is that potentials of RES are certainly not taken appropriately into account in the Slovenian NREAP that is why we have also tested compliance of RES potentials in Slovenia with NREAP.

\section{Methodology}

Statistical data presented in the study are gathered on the base of compilation method. Different independent sources (statistical offices, national, international and private studies and analysis, scientific papers and national energy balances) were used. Data of energy consumption, RES share, total, technical and economic RES potentials (exploited and unexploited), barriers of RES exploitation and all others data are statistically analyzed, evaluated and cross-compared.

Comparison energy production and RES share in Slovenia, EU and the world presents situation analysis. Our contribution is identification and combination of data, since individual data from different sources are not comparable because they were obtained by different methodologies. On this basis actual similarities and differences of energy statistics of Slovenia, EU and the world were than examined and cross-compared. In the second part RES potentials of Slovenia are examined. We examined and critically evaluated many existing studies, evaluations and documents. Where the deviations of RES potential between 
individual studies were large, comparison with our own calculations of RES potentials that was based on characteristics of Slovenia (natural and physical characteristic, theoretical energy conversions) was made. In case of solar potential, our estimation is calculated on the base of average annual solar radiation and multiplied with the total surface of Slovenia and in case of wood biomass potential, our calculation is based on annual natural forest increase and annual forest cut down and supported with the average heat of combustion. Our calculations and synthesis of many different data from different sources and characteristics of Slovenia presents the basis on which we made a comparison and compliance testing with the data and measures about RES potentials and measures written in Slovenian NREAP and national energy program (NEP).

The survey and analysis of Slovenian RES potentials is held on the basis of currently established economical, technological and environmental acceptability. We assume that technological and economic RES potential will increase in the future due to technological development, internalized external costs and increased prices of fossil fuel but the environmental potential will be reduced because of stricter environmental requirements. Although the study relates to NREAP that also includes calculations and forecasts about heat pumps, whose potentials are not yet fully discovered and liquid biomass that is mostly going to be imported in Slovenia, these two categories are not included in this study.

\section{Results and discussion}

\subsection{Energy consumption in Slovenia, EU and the World}

In order to achieve the development of sustainable energy policy all over the world, an international agreement, similar to $20 / 20 / 20$ objectives, that are obligatory for EU members, is necessary. Gross inland consumption of primary energy in Slovenia compared to EU and World in 2000 to 2009 is presented in Table 1. From table 1 it is also visible that in EU RES share and the production of energy from RES increases more successfully than in Slovenia. Calculation of trend, based on data from table 1, for years 2005 to 2009 has shown that EU-27 is reaching its target of renewable energy sources much faster than Slovenia itself.

Share of RES in Slovenian gross primary consumption is more or less constant from 2000 to 2009. The biggest share of RES in Slovenia belongs to wood and hydroelectric energy. Minor changes in RES share between 2000 and 2009 are mostly a result of hydrological conditions in Slovenia. RES share and energy production from RES is growing slowly; only from 2007, meanwhile RES share in EU-15, EU-25 and EU-27 is growing constantly from 2002. We have also compare Slovenia with the world energy statistic because we surprisingly found some similarities of Slovenia and the world, like later mentioned peak energy consumption or share of RES in world primary energy consumption that is like in Slovenia also more or less constant from 2000 to 2008. These pattern similarities are sometimes even stronger and more visible than similarities with EU pattern, although Slovenia is more similar to EU because it is a developed country above the world average from the energy use, GDP and standard of living point of view. However the world energy production from RES is growing. The cause is that the world growth of energy production from RES is the same as the growth of world primary energy consumption. Energy intensity in Slovenia slightly rose in 2008 and in 2009 it fall back to the level of 2007. Meanwhile EU energy intensity is continually declining since $2003[5,6]$. Peak of gross primary consumption in Slovenia was in 2008, while EU-15 reached peak consumption in 2005, EU-25 in 2005, EU-27 in 2006 and the world in 2007 [2, $5,6]$. A giant decline in energy production in 2009 can be seen in all analysed objects. This data among others also suggested cooling of economy, especially in most developed countries in EU and could be used as a forecast of economic trends in the near future. 
Energy demand in Slovenia exceeds Slovenian production capacity that is why Slovenia is going to import around $50.6 \%$ of its energy and energy sources in 2010. S lovenian dependency on energy imports (49\% in 2009) is very close to the EU-25 average (51\%). Both data shows that Slovenia and EU are highly dependent on energy imports. This dependency that causes economical, political and social vulnerability of EU members must be seen as a challenge and opportunity for sustainable energy policy. Slovenia is going to import $100 \%$ of hard coal, anthracite, coke and oil products along with $99.7 \%$ of natural gas. Domestic supply in year 2010 is based on lignite, brown coal, hydro energy, wood biomass and electric energy from nuclear power plant Krško [3]. Oil products will cover the biggest share, approximately $47.6 \%$, of imported energy sources [4]. Oil also remains the dominant fuel in the primary energy mix of EU-27 till 2035 [2].

Table 1. Total primary energy supply - TPES (2000-2009) [1, 2, 5, 6, 7].

\begin{tabular}{ccccccccccc}
\hline Slovenia & $\mathbf{2 0 0 0}$ & $\mathbf{2 0 0 1}$ & $\mathbf{2 0 0 2}$ & $\mathbf{2 0 0 3}$ & $\mathbf{2 0 0 4}$ & $\mathbf{2 0 0 5}$ & $\mathbf{2 0 0 6}$ & $\mathbf{2 0 0 7}$ & $\mathbf{2 0 0 8}$ & $\mathbf{2 0 0 9}$ \\
\hline TPES (ktoe) & 6360 & 6749 & 6820 & 6931 & 7129 & 7307 & 7318 & 7336 & 7749 & 6990 \\
RES (ktoe) & 761 & 776 & 716 & 714 & 822 & 774 & 768 & 735 & 845 & 874 \\
RES share (\%) & 12.0 & 11.5 & 10.5 & 10.3 & 11.5 & 10.6 & 10.5 & 10.0 & 10.9 & 12.5 \\
EU-15 & & & & & & & & & & \\
TPES (Mtoe) & 1454 & 1469 & 1502 & 1497 & 1530 & 1552 & 1552 & 1544 & 1527 & n.a. \\
RES (Mtoe) & 85 & 88 & 85 & 92 & 99 & 103 & 110 & 124 & 130 & n.a. \\
RES share (\%) & 5.8 & 6.0 & 5.7 & 6.2 & 6.5 & 6.6 & 7.1 & 8.0 & 8.5 & n.a. \\
EU-25 & & & & & & & & & & \\
TPES (Mtoe) & 1655 & 1668 & 1706 & 1702 & 1743 & 1766 & 1766 & 1764 & 1747 & n.a. \\
RES (Mtoe) & 90 & 93 & 97 & 95 & 103 & 111 & 115 & 123 & 137 & n.a. \\
RES share (\%) & 5.4 & 5.6 & 5.7 & 5.6 & 5.9 & 6.3 & 6.5 & 7.0 & 7.9 & n.a. \\
EU-27 & & & & & & & & & & \\
TPES (Mtoe) & 1724 & 1763 & 1759 & 1803 & 1825 & 1825 & 1826 & 1808 & 1799 & 1681 \\
RES (Mtoe) & 98 & 101 & 100 & 108 & 116 & 121 & 129 & 143 & 151 & 151 \\
RES share (\%) & 5.7 & 5.8 & 5.7 & 6.0 & 6.4 & 6.6 & 7.1 & 7.9 & 8.4 & 9.0 \\
World & & & & & & & & & & \\
TPES (Gtoe) & 10.02 & 10.17 & 10.23 & 10.58 & 11.04 & 11.44 & 11.60 & 12.06 & 12.00 & n.a. \\
RES (Gtoe) & 1.29 & 1.29 & 1.31 & 1.33 & 1.37 & 1.41 & 1.44 & 1.50 & 1.47 & n.a. \\
RES share (\%) & 12.9 & 12.7 & 12.8 & 12.6 & 12.4 & 12.3 & 12.4 & 12.4 & 12.3 & n.a. \\
\hline
\end{tabular}

From the energy mix analysis it is clear, that if we can not place our expectations on intensification of nuclear energy, we will need to focus our efforts into the development of renewable energy. Slovenia will have to restrict its attention to those technologies that could be introduced at a significant scale in the near future.

\subsection{Estimation, analysis and examination of RES potentials in Slovenia}

Because RES are the key element of sustainable energetics, we analysed and examined data about RES potentials in Slovenia. RES potentials are presented in table 2. Presented data and calculations from table 2 are not fully comparable, because they are combined from many different sources and studies of RES potentials in Slovenia that were or at least should be considered in preparing NREAP and NEP and compared with our own calculations. Differences also occur because forecasting RES potentials can not be totally reliable. Indicative prices for RES energy plants are as ubject of investments in electricity (cogeneration) power plants only. Investments in heating power plants are much lower. 
A hydro energy potential (HE) of Slovenia, a high efficiency of hydro electric power plants (HEPP), a very long life (over 100 years) and non-emission operation together with obtained cheap energy should make HEPPs the priority of the Slovenian energy industry. We estimate that the investments in large and small HE should be a priority of Slovenian electricity sector, because HEPP can significantly impact on mid-term replacement of CES. HE in Slovenia allows construction of small HE with additional $100 \mathrm{MW}$ installed power [8, 9]. Small HEPPs also have positive impact on the decentralization of energy industry and are over $90 \%$ efficient. Technical and economical potential of large HEPP is much higher than small HEPP potential but the construction of large HEPP causes a large local environmental impacts. Meanwhile small HEPPs cause much less environmental strain, can be built in many locations and require relatively small total investments, that is why small HEPPs are attractive also for private capital. Small HEPPs must also be encouraged in rural regions because they present social and economic benefits for rural development. Despite efficiency of HE exploitation can be improved also with renewing and upgrading existing HEPPs, Slovenia is not giving enough emphasis on this measure.

Table 2. RES potentials in Slovenia at the end of 2010 [ 5, 8, 9, 10, 11, 12].

\begin{tabular}{lcccccc}
\hline & $\begin{array}{c}\text { Total } \\
\text { potential } \\
(\mathrm{TWh} / \mathrm{a})\end{array}$ & $\begin{array}{c}\text { Technical } \\
\text { potential } \\
(\mathrm{TWh} / \mathrm{a})\end{array}$ & $\begin{array}{c}\text { Economical } \\
\text { potential by } \\
2020(\mathrm{GWh} / \mathrm{a})\end{array}$ & $\begin{array}{c}\text { NREAP } \\
2020 \text { goal } \\
(\mathrm{GWh} / \mathrm{a})\end{array}$ & $\begin{array}{c}\text { Price } \\
(\text { million } \\
\text { EUR/MW) }\end{array}$ & $\begin{array}{c}\text { Installed } \\
(\mathrm{MW})\end{array}$ \\
\hline Hydro & 19.4 & 9.1 & 6370 & 923 & & 819 \\
large HEPP & & $8.6-8.0$ & 6070 & 837 & $1.5-2.6$ & \\
small HEPP & & $0.5-1.1$ & 300 & 86 & $1.3-3.0$ & 90 \\
Solar & 25835.4 & $8.6-2777.8$ & $139-1300$ & 343 & $3.0-5.0$ & 17 \\
Wind & 15.6 & 3.1 & $226-1000$ & 191 & $1.0-1.4$ & 0 \\
Wood biomass & 19.6 & $2.9-10.1$ & $300-4305$ & 1249 & $2.0-4.5$ & 115.4 \\
Biogas & 47.3 & $2.8-4.3$ & $265-927$ & 255 & 3.6 & 20.5 \\
Geothermal & $>5.4$ & 0.6 & $44.4-150$ & 38 & 4.6 & 0 \\
\hline
\end{tabular}

Total potential of solar energy potential is approximately $25.84 \mathrm{PWh} / \mathrm{year}$. As we can see from table 2, technical potential is estimated approximately from 0.01 to $2.77 \mathrm{PWh} /$ year [11]. If we would like to achieve the maximum value of technical potential which is $10.8 \%$ of total potential, we should cover $10.8 \%$ of Slovenia's surface that is why we estimate this as an unrealistic value. However we have been witnessed 300\% growth of photovoltaic in year 2009 [12]. High growth is expected also in 2010. The reasons are the current level of operating support and guaranteed purchase price. However reference costs will be $20 \%$ lower in 2011 and 30\% lower in 2012 therefore moderate growth can be expected in the future.

Wind energy potential in Slovenia is currently totally unexploited. Total installed capacity of wind power plants (WPP) in Slovenia is $0 \mathrm{MW}$ [12] despite the fact that wind is one of the cleanest and fastest growing RES on the world and especially in EU. The usage of WPP is limited due to lack of appropriate geographic locations, as well as the fact that almost $36 \%$ of Slovenia is included into NATURA 2000 network. Although construction of WPP represents significant intervention in the environment, we can achieve synergy with nature by thoughtful and sustainable positioning of WPPs, especially in degraded areas near roads. We propose the installation of a few pilot WPPs and the examination of their functioning. The results obtained would facilitate the decisions about new investments in WPPs and critics of environmental organizations which do not support WPPs in Slovenia. We have witnessed some unsuccessful investments in installations of WPP, therefore Slovenia is going to study and analyse proper areas for WPP. Because of the trends of WPP in EU, Slovenia's department for energy is 
going to make a list of environmentally undisputed areas with sufficient wind that would attract potential investors. This measure will enable faster commercialization of wind energy.

Maximal technical potential of wood biomass estimated in NREAP and NEP seems excessively high. Technical potential is indeed estimated from 2,875 to $10,108 \mathrm{GWh}$ /year [11]. However estimation $2,875 \mathrm{GWh} /$ year covers only wood biomass that can be exploited only in minor energy plants and households, while maximum estimation covers also wood biomass that can be exploited in major energy plants and as co-incineration in thermal power plants. In spite of that, differences in wood biomass potential estimations are significant and very different from our calculation. Annual natural forest increase in Slovenia is $8 \mathrm{~m}$ illion cubic meters and average energy potential calculated from average heat of combustion of eleven different types of domestic Slovenian wood is $2,440 \mathrm{GWh}$ per million cubic meters of wood $[11,13]$. That means that for achieving maximal technical potential Slovenia should exploit approximately one half of annual forest increase what is almost impossible, because of wood processing industry and current annual cut down that is approximately 3 million cubic meters of wood. Because of that we believe that this estimation is overestimated. Although NREAP goal for wood biomass is ambitiously set, wood biomass increase will have to be well supported for achieving the objective.

Relatively high biogas potential of Slovenia also seems to be overestimated. In similar studies which were not included in the preparation of NREAP and NEP (like the study of BigEast), estimated technical and total potential is much smaller. However, the NREAP goal is not so ambitiously set, because the study made by Agricultural and forestry chamber, that was not included in the preparation of NREAP and NEP, estimates that biogas potential by 2020 is $927 \mathrm{GWh} /$ year [13] which is almost four times more than the NREAP goal is for 2020.

Slovenia currently exports a lot of biological waste to Austria [4]. Instead of this we believe that Slovenia should search for options for bigger domestic exploitation of biological waste. Important emphasis also must be made on cogeneration of heat and electricity and more extended use of landfill gas. Especially problematic is the use of heat from biogas plants, because they are mainly in the areas where not many heat consumers live. Slovenia should also support the cooperation between local farmers and local communities that should become partners in biogas plant investments. This kind of partnership is very appropriate for rural development and for preserving jobs in rural areas that means that positive effects of biogas as a RES are not just a matter of energy policy. Future measures are appropriate, because exploitation of biogas has strong growth. Growth from 2008 to 2009 was considerable $117 \%$. Despite the enshrined measures, the main problem of biomass exploitation, whether to exploit rural areas for food or for energy corps supply remains the same.

Estimated geothermal energy potential of Slovenia differs greatly in different sources and studies. Geothermal energy potential data are collected every 5 years. Last available data are from year 2005, therefore Slovenian geothermal potential can not be accurately estimated. Nevertheless we can say the annual potential is at least $5443 \mathrm{GWh}$ [11].

As it is evident in table 2 comments, NREAP has both good and bad sides and does not only deal with RES potentials but is also a plan for the future state of Slovenian energy sector.

\subsection{Key factors for forecasting and planning future energy policy in Slovenia}

Whereas the preparation of NREAP is a challenging project, only four members of EU have managed to submit NREAP in time (until 30.6.2010) and six members still did not submit it 
until the end of 2010. Slovenian NREAP was submitted to EC with minor delay (8.7.2010) which is a result of completion and improvement of the NREAP content. Slovenian energy consumption forecasts and goals are presented in table 3. Calculation of future energy use in Slovenia for 2016, directed with 2006/32/EC, is based on 2006/32/EC directive methodology.

Table3. Forecasting and planning final energy consumption (FEC) for achieving 20/20/20 or 25 objectives $[3,10,11]$

\begin{tabular}{|c|c|c|c|c|c|c|c|c|}
\hline category & 2007 & 2008 & 2009 & $\begin{array}{c}\text { 2009 } \\
\text { evaluation }\end{array}$ & $\begin{array}{c}\mathbf{2 0 1 0} \\
\text { forecast }\end{array}$ & $\begin{array}{c}2012 \\
\text { forecast } \\
\text { (Kyoto) }\end{array}$ & $\begin{array}{c}\mathbf{2 0 1 6} \\
\text { objective } \\
(-9 \%)\end{array}$ & $\begin{array}{c}\mathbf{2 0 2 0} \\
\text { objective } \\
(20 / 20 / 20)\end{array}$ \\
\hline FEC in & & & & $4960-$ & $4744 /$ & & $4267(9 \%)$ & $5232 *$ \\
\hline Slovenia (ktoe) & 4867 & 5232 & 4891 & 5176 & $4927 *$ & $5031 *$ & / 5214* & or “ $x "$ \\
\hline RES in FEC in & & & & & $840 /$ & & & $1324^{*}$ or \\
\hline Slovenia (ktoe) & 745 & 780 & 787 & $813-849$ & $872 *$ & $941 *$ & $1137 *$ & 0.25 “' $x$ " \\
\hline RES share in & & & & & & & & \\
\hline Slovenia (\%) & 15.3 & 14.9 & 16.1 & 16.4 & 17.7 & 18.7 & 21.8 & 25.3 \\
\hline RES share in & 97 & 103 & 110 & $n a$ & 120 & $n$ & $n$ & 200 \\
\hline 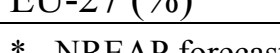 & 9.1 & 10.5 & 11.0 & 11.a. & & illa. & & \\
\hline
\end{tabular}

In the table $3 \mathrm{w}$ e can see that NREAP plan shows 20/20/20 objectives are achievable at Slovenian and EU level. Because 2020 goals do not prescribe future energy consumption but only the share of RES, we marked energy consumption in $2020 \mathrm{w}$ it " $x$ ". For 20/20/20 objectives future energy consumption is not so important but it is essential that RES share advocates $25 \%$ of " $x$ ". Especially important and problematic for achieving $25 \%$ of RES in Slovenia is raising share of transport [10] that is becoming the biggest problem in meeting Kyoto GHG emission targets as well. The lack of implementation of past objectives can also be seen in NREAP planning. Objective 33.6\% of electricity from RES, set for 2010 for example, is planned to be reached (exceeded) only by 2015. In table 3 we can also see that NREAP objective is not planning to lower final energy consumption but to lower its growth. Because smaller and energy efficient use is also the goal of EU and because energy use declined in 2009 [5], mainly because of the economic crisis, we only have to retain it on the current level, what is more favorable than reducing it. That is why this is not a very ambitious goal. NREAP is actually planning to breach 2006/32/EC directive, which directs Slovenia to achieve 9\% energy savings relative to the annual average energy consumption of 2001-2005 by 2016. We believe that increased EE and gradual change of consumer habits should be fully included in NREAP, because this brings the best long-term opportunity for smaller and efficient energy use. However it is realistic to expect a smaller growth of energy consumption by 2015 due to economic recovery but this trend must be limited already in the present.

Disregarding Kyoto targets can also be seen. Planed closure of inefficient blocks of thermal power plant could be made in 2012 instead of 2014 [8]. With this measure Slovenia would significantly reduce possible penalty for failing Kyoto targets and improve the basis for the South Africa agreement as a successor to the Kyoto.

\section{Conclusions}

In the study we have proven that studies and data about RES potentials differ significantly. That makes the estimates about RES potentials and future energy policy goals planning partly inaccurate. We discovered that our calculations about RES potentials are not exactly the same as in NREAP and NEP therefore we are not totally sure about appropriateness of goals and 
measures set by Slovenian energy policy. Possible cause of differentiation of different studies about RES potential could be inaccurate data, different databases or different methodology of some studies. It is also possible that data presented in NREAP and NEP could be more accurate if more studies and researches about RES potentials would be made. However, all the studies had shown that Slovenia has many unexploited RES potentials, especially hydro, solar and wood biomass potentials, which are appropriate for future exploitation from technological, economical and environmental point of view, therefore they must be particularly stimulated. NREAP goals are ambitiously set and high growth of RES in all four sectors of NREAP is planned. Wood biomass and hydro potential will be increased most of all. Our opinion is that achieving these goals will be the most problematic. We have also noticed the lack of ambitious measures for smaller and energy efficient use, based on cogeneration or threegeneration, that could also be based on the 2006/32/EC directive.

We believe that reduced and efficient energy use is the only solution that leads to the sustainable energetics. Most important is that efficient technologies will be used regardless of the RES and that measures regarding RES and EE will be combined and implemented.

\section{References}

[1] H. Komiyama, S. Kraines, Vision 2050: Roadmap for a Sustainable Earth, Springer, 2008.

[2] International Energy Agency (IEA), WORLD ENERGY OUTLOOK 2010 FACTSHEET, IEA, 2010.

[3] Ministry for Economy, Energy balance for the Republic of Slovenia for the year 2010, 2010, (in the Slovenian language).

[4] Environmental Agency of the Republic of Slovenia, Environmental indicators of Slovenia, available on: http://kazalci.arso.gov.si/, [10.12.2010], 2010, (in the Slovenian language).

[5] SURS Statistical Office of Republic of Slovenia. Annual Energy Statistic 2009 - final data, 2010, (in the Slovenian language).

[6] EUROSTAT, Energy statistics - main indicators and quantities, EUROSTAT, 2010.

[7] Federal Ministry for the Environment, Nature Conservation and Nuclear Safety, Renewable Energy Sources in Figures - National and International Development, 2010.

[8] M. Obrecht, M. Denac, Evaluation of potential and options of renewables for development of sustainable energy in Slovenia, Facing the Challenges of the Future: Excellence in Business and Commodity Science, 17th IGWT Symposium and 2010 International Conference on Commerce, 2010.

[9] Holding Slovenske elektrarne, HSE and RES in Slovenia, 2010, (in the Slovenian language).

[10] NREAP, National Renewable Energy Action Plan, Ministry of the Economy, 2010.

[11] Jožef Štefan Institute, National energy program (NEP) 2010 Long-term energy balance 2010 to 2030, Ministry of the Economy, 2010, (in the Slovenian language).

[12] Energy Agency of the Republic of Slovenia, Register of declarations for the production facilities of electricity from renewable sources and high-efficiency cogeneration, 2010, (in the Slovenian language).

[13] Agricultural and forestry chamber, Data about wood biomass and biogas in Slovenia, available on: http://www.kgzs.si/gv/gozd/les-in-biomasa.aspx, [25.11.2010], 2010. 